\title{
ASSOCIATION OF SELF-REPORTED SYMPTOMS OF XEROSTOMIA WITH VAPING AND CIGARETTE SMOKING: A CROSS-SECTIONAL STUDY
}

\author{
Ali M. Hasan', Rasha Salah', Firas A. Farhan³, Ali A. Abdulkareem² \\ 'Department of Oral and Maxillofacial Surgery, College of Dentistry, University of Baghdad, Iraq \\ 2Department of Periodontics, College of Dentistry, University of Baghdad, Iraq \\ ${ }^{3}$ Department of Prosthodontics, College of Dentistry, University of Baghdad, Iraq
}

\begin{abstract}
INTRODUCTION: Vaping was first introduced as safe alternative to smoking and as a promising method to quit smoking. However, with the passage of time, cumulative adverse effects of this new device on general and dental health start to emerge. Xerostomia is known to be associated with cigarette smoking but this effect is not well explored with vaping.

ОвJECTIVEs: This study aimed to investigate the association of self-reported xerostomia with vaping and cigarette smoking.

MATERial AND METhods: A questionnaire was designed to collect demographic data including age, gender, employment status, and educational level. Smoking-related data were also collected including reason for using vaping devices, frequency and duration of smoking methods. The last part aimed to estimate xerostomia via a 5-point Likert scale.

RESULTS: A total of 732 participants (25.4\% cigarette smokers, $63.8 \%$ vapers, $10.8 \%$ never-smokers) were included in the final analysis. The analysis showed that cigarette smokers had significantly higher xerostomia scores than the other two groups. Similarly, xerostomia scores of individuals using vaping was significantly higher than never-smokers. Further analysis showed that subjects in the cigarette smoker group, with high school education or below, had significantly higher scores than other educational levels. For vapers, increasing frequency of vaping $>20$ days/month significantly increased symptoms of xerostomia.

ConcLusions: Xerostomia is an expected and highly perceived symptom among cigarette smokers. Vape device users also may experience symptoms of xerostomia more than never-smokers.
\end{abstract}

KEY wORDs: tobacco smoking, vaping, e-cigarettes, xerostomia.

J Stoma 2021; 74, 3: 188-194

DOI: https://doi.org/10.5114/jos.2021.109183

\section{INTRODUCTION}

Smoking is a negative behavior pattern with many well-documented adverse health and social consequences on a global scale. Indeed, smoking is an independent risk factor for the development of several systemic diseases and also impaired prognosis of the treatment $[1,2]$.

The concept of vaping was first introduced by a Chinese pharmacist, Hon Lik, in the early $21^{\text {st }}$ century, as a safe alternative to smoking [3]. It is a battery-operated

JOURNAL OF STOMATOLOGY CZASOPISMO STOMATOLOGICZNE

ADDRESS FOR CORRESPONDENCE: Dr. Ali A. Abdulkareem,

Department of Periodontics, College of Dentistry, University of Baghdad, Iraq, e-mail: ali.abbas@codental.uobaghdad.edu.iq 
device containing heating coil and a liquid tank. The principle of action for vaping depends on heating liquids to release a chemical-filled aerosol for inhalation [4]. This liquid contains nicotine and artificial flavorings, such as menthol and candy [4]. This smoking device is characterized by a fragrant smell, good flavor and the production of vapor instead of smoke together with its exotic and trendy appearance and the claims for its safety for indoor use [5]. For these reasons, vape devices tipped the scale against traditional smoking methods and there has been a dramatic increase in the popularity of vaping over the last decade $[6,7]$.

According to a survey study from the USA [8], vaping was more prevalent in younger (aged 18-24 years) than in older individuals (65 years and older) and among males than females. Further, nearly $10 \%$ of nevercigarette smokers had vaped at least once [8]. The most commonly reported reasons for using vape devices were as an attempt to quit cigarette smoking and for social entertainment [9]. Moreover, vaping is generally perceived as safer than tobacco smoking [10]. However; studies reported that exposure of gingival epithelial cells, human periodontal ligament and lung fibroblasts to the vapor of e-smoking devices has been associated with the production of pro-inflammatory cytokines and upregulation of the receptor for advanced glycation end products $[4,10]$. Furthermore, in vitro studies showed that aerosols generated from these devices could cause the formation of reactive oxygen species, which result in DNA damage, decrease cell viability and promote cell apoptosis and necrosis [11].

Saliva is a complex body fluid that is essential to oral health [12]. It is required for the protection of oral mucosa, digestion, tooth remineralization, $\mathrm{pH}$ balance, taste sensation and phonation. It consists of a variety of electrolytes, peptides, glycoproteins and lipids which have antimicrobial, antioxidant, tissue repair, and buffering properties [13]. Alteration in the whole-mouth salivary flow rate (SFR) plays an important role in the pathogenesis of oral and dental diseases [14]. Reduced SFR is associated with xerostomia, also known as true xerostomia, or it could be pseudo-xerostomia, which is defined as "a subjective feeling of oral dryness despite normal function of salivary glands" [15]. Globally, the prevalence of xerostomia ranges from 12 to $30 \%$ with menopausal women and elderly subjects ( $\geq 65$ years) being the most affected [16]. In fact, xerostomia is considered as a manifestation of other underlying pathologic or psychological conditions, affecting the normal function of salivary glands, rather than being an independent clinical entity [17]. These conditions include diabetes mellitus, hyperthyroidism, avitaminosis, depression, salivary gland disease, Sjögren syndrome, and medications [18]. It is known that long-term/heavy smoking results in a significant reduction of the SFR and increases oral and dental disorders related to xerostomia, especially cervical caries, gingivitis, tooth mobility, calculus and halitosis [19]. To the best of our knowledge, limited studies have investigated the physiologic effect of vaping as a contributor to xerostomia.

\section{OBJECTIVES}

The aim of this study was to investigate the association of self-reported symptoms of xerostomia with vaping and cigarette smoking.

\section{MATERIAL AND METHODS}

\section{STUDY DESIGN AND POPULATION}

This was a cross-sectional questionnaire-based survey study that was carried out from July 2019 to January 2020. The questionnaire was distributed among participants in randomly selected coffee shops and clubs in Baghdad city. The study was conducted after obtaining approval from the ethics committee in consistency with the Helsinki declaration for human research.

Inclusion criteria:

- age $\geq 18$ years,

- both sexes,

- non-alcoholic,

- no history of systemic conditions such as thyroid disease, diabetes mellitus, or renal disease,

- no salivary gland disease,

- for vapers, the vape juice should contain nicotine,

- individuals using one smoking method, i.e., cigarette smoking or vaping only, together with never-smokers (control).

Exclusion criteria:

- mouth-breathers,

- elderly people (age $\geq 65$ years) [20],

- medication causing xerostomia as a side-effect e.g., diuretics, antihypertensive, antihistamine, and antidepressants,

- patients currently under chemotherapy or radiotherapy,

- not willing to participate,

- individuals using multiple smoking methods simultaneously,

- former smokers.

The aims of the study were clearly mentioned to the eligible participants before signing the consent form.

\section{QUESTIONNAIRE'S ELEMENTS AND SCORING}

The questionnaire consisted of three parts. The first one was dedicated to collection of information regarding age, sex, history of systemic disease/condition, use of any medication, employment status, and educational level. The second part consisted of questions about smoking method, reason for using/switching to vaping, 
TABLE 1. Components of the questionnaire

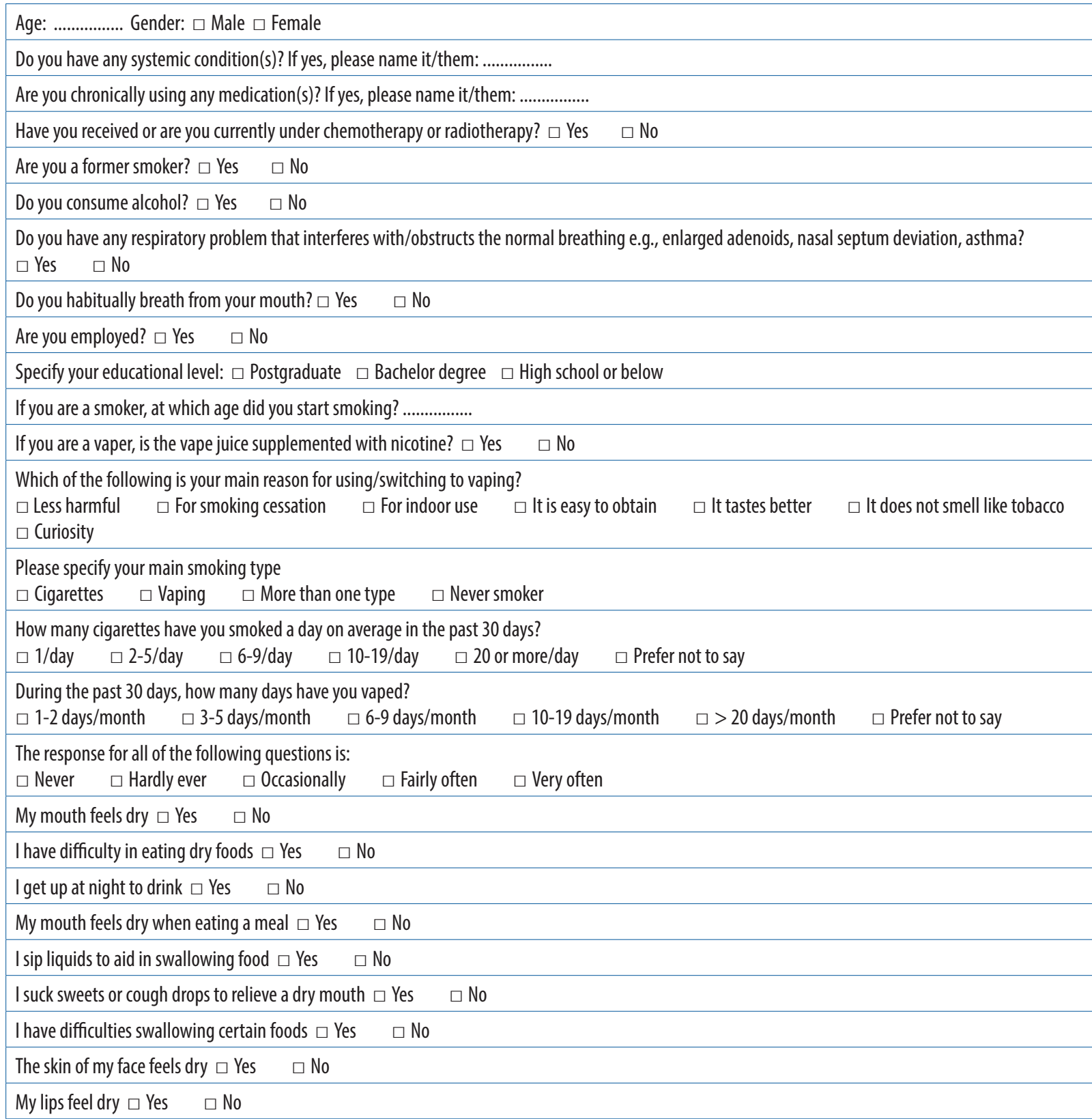

duration and frequency of smoking. The last part comprised 9 questions and the response was based on 5-point Likert scale, namely "Never", "Hardly ever", "Occasionally", "Fairly often", "Very often". The latter responses were given scores 1, 2, 3, 4, 5 respectively. The xerostomia sensation was determined by asking the participants these particular questions about xerostomia. The total scores of all questions, for each participant, were summed and used later for the analysis.

The questionnaire was translated into Arabic and was administered to all individuals by two of the authors. Enough time was given for the participants to complete the forms before they were re-collected by the same authors. Components of the questionnaire used in this study are illustrated in Table 1.

\section{SAMPLE SIZE}

The targeted population comprised resident people of Baghdad city. According to the latest available statistics, the population of this city is $7,144,000$. Sample size was calculated according to the following formula:

$n=\mathrm{z}^{2} \mathrm{P}(1-\mathrm{P}) / \mathrm{d}^{2}$,

where $n$ is the sample size, $z$ (confidence interval at $95 \%)=1.96, P($ expected prevalence $)=0.5, d$ (error margin $)=0.05$. True sample size then was calculated according to the following formula:

True sample $=($ sample size $\times$ population $) /$

/(sample size + population -1$)$.

Accordingly, the calculated sample size is 384 . This number was rounded to 400 and multiplied by 3 to avoid 
possible drop out of the participants. Therefore, a total of 1200 questionnaires were required to be distributed among eligible participants.

\section{STATISTICAL ANALYSIS}

The data were statistically analyzed using computerbased software (SPSS, Version 22 for Windows, IBM, Armonk, NY, USA). Mean, standard deviation, frequen$c y$, and percent were used as descriptive statistics. Inferential analysis was performed with the $\chi^{2}$ test for categorical variables. Continuous variables were analyzed by ANOVA test for parametric data while Mann-Whitney and Kruskal-Wallis tests were used for non-parametric data. Age groups and duration of smoking/vaping were dichotomized according to the median of each smoking method. Statistical significance was considered when the $p$-value was less than 0.05 at the $95 \%$ confidence level.

\section{RESULTS}

A total of 1200 individuals were invited to participate in the present study. Initially, 336 participants were excluded for different reasons. Later, another 132 participants were excluded before the analysis as they were using multiple smoking methods, leaving 732 (61\% response rate) participants for the final analysis (Figure 1). The participants were classified according to different demographic and smoking characteristics (Table 2). Significant differences were observed among cigarette smoker, vaper, and never-smoker groups in relation to different variables including age, duration of smoking, sex, employment status, and educational level (Table 3).

For reasons of using/switching to vaping, the majority of participants thought that vaping is less harmful than smoking ( $n=252,54.0 \%$ ) followed by using it as a method to quit smoking $(n=96,20.6 \%)$ (Table 4$)$.

Further analysis of total xerostomia scores indicated significant difference among all groups. In detail, the mean score in the cigarette smoker group was significantly higher $(p<0.001)$ than in both never-smoker and vaper groups. In addition, total scores of individuals using vape device were significantly higher $(p<0.05)$ than the never-smoker group (Table 5).

Subgroup analysis according to different independent variables showed that no significant differences were observed in cigarette smokers expect for educational level where scores of "High school and below" were significantly higher than the other two subclasses (Table 5). For vapers, also no significant differences were observed except for frequency of vaping, in which those who vape $>20$ days/month had significantly higher scores than those vaping $\leq 10$ days/month (Table 5). For never-smokers, only employed individuals showed significantly higher xerostomia scores than unemployed counterparts (Table 5). Comparison according to gender

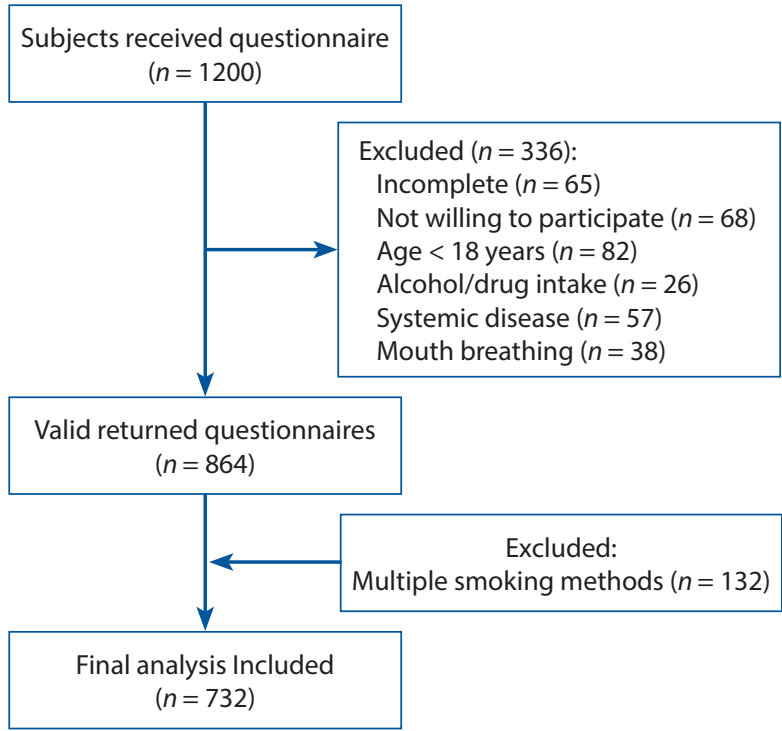

FIGURE 1. Flow chart of the study

TABLE 2. Demographic characteristics and details of the study population

\begin{tabular}{|l|c|}
\hline \multicolumn{2}{l|}{ Variables } \\
\hline Age (years), mean \pm SD & $27.3 \pm 7.7$ \\
\hline Age range; median (years) & $18-55 ; 27$ \\
\hline \begin{tabular}{l} 
Sex, $n(\%)$ \\
\hline Male
\end{tabular} & $703(96.0)$ \\
\hline Female & $29(4.0)$ \\
\hline Employment status, $n(\%)$ & $507(69.3)$ \\
\hline Employed & $225(30.7)$ \\
\hline Unemployed & \\
\hline Educational level, $n(\%)$ & $85(11.6)$ \\
\hline Postgraduate & $382(52.2)$ \\
\hline Bachelor degree & $265(36.2)$ \\
\hline High school and below & $732(100)$ \\
\hline Total &
\end{tabular}

was not performed due to the small number of females in cigarette and vaper groups.

\section{DISCUSSION}

The use of vape devices is escalating specially among cigarette smokers trying to quit smoking $[21,22]$. Growing evidence supports the general perception that vaping is less harmful than traditional cigarettes [23-26]. The main results showed that vaping could contribute to the increased feeling of xerostomia. Vaping is not completely harmless and side effects have been reported $[27,28]$. Although the reported harmful/adverse effects of vaping are at a lower level than those of cigarettes [29], 
TABLE 3. Analysis of demographic characteristics and details of the study population according to smoking/vaping methods

\begin{tabular}{|c|c|c|c|c|}
\hline Variables & Cigarette & Vaping & Never-smoker & $p$-value* \\
\hline Age, mean $\pm S D$ (years) ${ }^{\ddagger}$ & $29.7 \pm 8.1$ & $26.6 \pm 7.5$ & $27.0 \pm 7.8$ & $<0.001$ \\
\hline Age range, median (years) & $18-58 ; 29$ & $18-55 ; 25$ & $18-52 ; 25$ & \\
\hline \multicolumn{5}{|l|}{ Sex, $n(\%)$} \\
\hline Male & $181(97.3)$ & $464(99.4)$ & $58(73.4)$ & \multirow[t]{2}{*}{$<0.001$} \\
\hline Female & $5(2.7)$ & $3(0.6)$ & $21(26.6)$ & \\
\hline \multicolumn{5}{|l|}{ Employment status, $n(\%)$} \\
\hline Employed & $152(81.7)$ & $301(64.5)$ & $54(68.4)$ & \multirow[t]{2}{*}{$<0.001$} \\
\hline Unemployed & $34(18.3)$ & $166(35.5)$ & $25(31.6)$ & \\
\hline \multicolumn{5}{|l|}{ Educational level, $n$ (\%) } \\
\hline Postgraduate & $22(11.8)$ & $39(8.4)$ & $24(30.4)$ & \multirow[t]{3}{*}{$<0.001$} \\
\hline Bachelor degree & $114(61.3)$ & $262(56.1)$ & $6(7.6)$ & \\
\hline High school and below & $50(26.9)$ & $166(35.5)$ & $49(62.0)$ & \\
\hline Smoking status $s^{\S}$ & $186(25.4)$ & $467(63.8)$ & $79(10.8)$ & \\
\hline \multicolumn{5}{|l|}{ Frequency of smoking $^{\dagger}$} \\
\hline$\leq 10$ & $28(15.1)$ & $43(9.2)$ & - & \\
\hline $11-20$ & $80(43.0)$ & $48(10.3)$ & - & \\
\hline$>20$ & $78(41.9)$ & $376(80.5)$ & - & \\
\hline Duration of smoking mean \pm SD (years) $^{\#}$ & $11.9 \pm 7.2$ & $6.1 \pm 4.7$ & - & $<0.001$ \\
\hline
\end{tabular}

TABLE 4. Reported reasons for using/switching to vape device

\begin{tabular}{|l|c|c|}
\hline Reasons & Frequency & Percent \\
\hline Less harmful & 252 & 54.0 \\
\hline For smoking cessation & 96 & 20.6 \\
\hline For indoor use & 5 & 1.1 \\
\hline It is easy to obtain & 3 & 0.6 \\
\hline It tastes better & 51 & 10.9 \\
\hline It does not smell like tobacco & 41 & 8.8 \\
\hline Curiosity & 19 & 4.1 \\
\hline Total & 467 & 100.0 \\
\hline
\end{tabular}

potential public health benefits of vaping should be weighed against possible health risks [30,31].

According to the results of our study most individuals used or switched to vaping because they thought it was less harmful than cigarettes (54.0\%) and it could be a good approach to quit smoking (20.6\%). This is consistent with results from other studies $[9,10]$. Those individuals are well educated and aware about the harmful effects of smoking cigarettes and were inclined to use a less harmful alternative. This was evident in this study as the prevalence of vaping was higher among highly educated subjects. In fact, relapse to smoking is a com- mon behavior of ex-smokers who switched to vaping, as demonstrated by a current longitudinal survey in the UK [32].

A number of studies have demonstrated that smoking is one of the risk factors for xerostomia [19, 33, 34]. It seems that smoking increases the activity of salivary glands in subjects who begin smoking, but in long-term use it decreases the SFR [35]. In order to study the association between different types of smoking and symptoms of mouth dryness, a questionnaire was developed with questions that are indicative of the presence of xerostomia. It seems that these questions, especially the ones about feeling of xerostomia during eating and swallowing, are extremely important, and can correctly indicate xerostomia [36]. Our study has shown results comparable to those of the aforementioned studies. Smoker subjects who experienced xerostomia symptoms significantly outnumbered vapers and never-smokers. This finding could be attributed to the fact that cigarette smokers showed significantly longer duration of smoking than their counterparts in the vaping group. This is an expected result as vaping is a relatively new concept that gained popularity only in the last decade [3]. This is also evident from the significantly older age of subjects consuming cigarettes and those using vape devices, in agreement with a previous survey indicating that younger populations are more attracted to vaping [8]. Therefore, subjects who had the habit of cigarette smoking for a longer period are 
more likely to develop more severe symptoms of xerostomia. Despite that, the results indicated increased sensations of xerostomia among cigarette smokers as compared to vapers. However, symptoms of xerostomia were significantly more numerous in vapers as compared to never-smokers. This finding is in accord with the results of a survey study that identified xerostomia as the most commonly reported side effect of vaping [29].

Employed individuals showed higher feeling of xerostomia than the unemployed in the never-smoker group. This could be explained by decreasing salivary secretion and increased sensation of mouth dryness due to physical and mental stress of the work environment [37]. Interestingly, this finding was not observed among cigarette smokers or vapers regardless of their employment status. This may indicate that increased xerostomia symptoms due to any smoking/vaping method used obscured stress-related mouth dryness, which further supports the stated hypothesis for this study. Furthermore, increasing frequency of using vape devices was associated with significant increase in xerostomia symptoms. This suggests that the adverse effect of vaping on SFR is dependent on how frequently these devices are used.

Indeed, no subjective measure of oral dryness is in itself sufficient to diagnose deficiency of saliva, but these symptoms appear to be very revealing and subjects with these symptoms may require additional investigation. The current study has some limitations including lack of objective measurements of salivary volume, which was mainly limited due to the setting of the study that aimed to collect the data from public, outdoor places. In addition, the number of females who admitted their smoking habits was very low, which is related to the tradition and cultural restrictions that consider smoking as a shameful habit for the females. Furthermore, the diversity of vaping devices, liquids used and variations in their design and specifications, e.g., preferred amperage, number of coils, limited the standardizations for this method. Although the use of questionnaires is acceptable as reliable evaluation tools for assessment of self-reported subjective well-being of individuals $[38,39]$, their outcomes depend on the recall capabilities of the subjects. Based on these limitations, these results should be interpreted with caution and further investigations are highly recommended.

\section{CONCLUSIONS}

The main finding of this study was that the sensation of xerostomia associated with cigarette smoking was well recognized. However, vaping also could result in perceptible symptoms of xerostomia. Additionally, the general attitude about vaping as less harmful and a good way to cease smoking is not necessarily correct. Therefore, public health programs are needed for educating users of vape devices about their potential adverse effects.
TABLE 5. Comparison of xerostomia scores among groups according to different independent variables

\begin{tabular}{|c|c|c|c|}
\hline Variables & Cigarettes & Vaping & $\begin{array}{l}\text { Never- } \\
\text { smoker }\end{array}$ \\
\hline Smoking method & $20.2 \pm 6.1^{* *}$ & $16.3 \pm 5.7^{*}$ & $14.0 \pm 2.5$ \\
\hline \multicolumn{4}{|l|}{ Age groups (years) } \\
\hline$\leq 29$ & $20.9 \pm 6.1$ & - & - \\
\hline$>29$ & $19.3 \pm 6.0$ & - & - \\
\hline$\leq 25$ & - & $16.3 \pm 5.9$ & $13.6 \pm 2.5$ \\
\hline$>25$ & - & $16.1 \pm 5.4$ & $14.5 \pm 2.3$ \\
\hline
\end{tabular}

\begin{tabular}{|c|c|c|c|}
\hline \multicolumn{4}{|l|}{ Employment status } \\
\hline Employed & $20.0 \pm 6.2$ & $16.6 \pm 5.8$ & $14.7 \pm 2.5^{*}$ \\
\hline Unemployed & $20.6 \pm 5.6$ & $15.7 \pm 5.4$ & $13.2 \pm 2.1$ \\
\hline \multicolumn{4}{|l|}{ Educational level } \\
\hline Postgraduate & $17.5 \pm 4.2$ & $15.8 \pm 5.4$ & $15.0 \pm 2.0$ \\
\hline Bachelor degree & $19.6 \pm 5.9$ & $16.3 \pm 5.6$ & $14.3 \pm 2.6$ \\
\hline High school and below & $22.5 \pm 6.5^{*, a}$ & $16.1 \pm 5.8$ & $13.5 \pm 2.4$ \\
\hline
\end{tabular}

\begin{tabular}{|c|c|c|c|}
\hline \multicolumn{4}{|c|}{ Frequency of smoking/vaping ${ }^{\dagger}$} \\
\hline$\leq 10$ & $19.1 \pm 5.6$ & $15.7 \pm 5.6$ & - \\
\hline $11-20$ & $19.8 \pm 6.3$ & $17.2 \pm 5.5$ & - \\
\hline$>20$ & $20.8 \pm 5.9$ & $17.4 \pm 5.7^{*, \mathrm{~b}}$ & - \\
\hline \multicolumn{4}{|c|}{ Duration of smoking (years) } \\
\hline$\leq 11$ & $20.9 \pm 6.3$ & - & - \\
\hline$>11$ & $19.3 \pm 5.7$ & - & - \\
\hline$\leq 5$ & - & $16.1 \pm 6.0$ & - \\
\hline$>5$ & - & $16.3 \pm 5.3$ & - \\
\hline
\end{tabular}

* Significance level at $p<0.05$, Kruskal-Wallis and Mann-Whitney test. Asterisk indicates significantly higher score. ${ }^{\dagger}$ Frequency for cigarette smoking: cigarettes/day, for vaping: days/month. ${ }^{a} \mathrm{High}$ school and below significantly different than other two groups. ${ }^{B}>20$ group significantly different from $\leq 10$ group

\section{CONFLICT OF INTEREST}

The authors declare no potential conflicts of interest with respect to the research, authorship, and/or publication of this article.

\section{References}

1. Vellappally S, Fiala Z, Smejkalová J, Jacob V, Somanathan R. Smoking related systemic and oral diseases. Acta Medica (Hradec Kralove) 2007; 50: 161-166.

2. Mallampalli A, Guntupalli KK. Smoking and systemic disease. Clin Occup Environ Med 2006; 5: 173-192, x.

3. Bhatnagar A, Whitsel LP, Ribisl KM, et al. Electronic cigarettes: a policy statement from the American Heart Association. Circulation 2014; 130: 1418-1436.

4. Sundar IK, Javed F, Romanos GE, Rahman I. E-cigarettes and flavorings induce inflammatory and pro-senescence responses in oral epithelial cells and periodontal fibroblasts. Oncotarget 2016; 7: 77196 .

5. Romijnders K, Pennings JLA, van Osch L, de Vries H, Talhout R. A combination of factors related to smoking behavior, attractive 
product characteristics, and socio-cognitive factors are important to distinguish a dual user from an exclusive e-cigarette user. In J Environ Res Public Health 2019; 16: 4191.

6. Kennedy RD, Awopegba A, De León E, Cohen JE. Global approaches to regulating electronic cigarettes. Tob Control 2017; 26: 440-445.

7. Grana R, Benowitz N, Glantz SA. Background paper on e-cigarettes (electronic nicotine delivery systems). UCSF: Center for Tobacco Control Research and Education; 2013. Available from https://escholarship.org/uc/item/13p2b72n.

8. Schoenborn CA, Gindi RM. Electronic cigarette use among adults: United States, 2014. NCHS data brief 2015; 1-8.

9. Ayers JW, Leas EC, Allem JP, et al. Why do people use electronic nicotine delivery systems (electronic cigarettes)? A content analysis of Twitter, 2012-2015. PLoS One 2017; 12: e0170702.

10. Chapman SLC, Wu LT. E-cigarette prevalence and correlates of use among adolescents versus adults: a review and comparison. J Psychiatr Res 2014; 54: 43-54.

11. Anderson C, Majeste A, Hanus J, Wang S. E-cigarette aerosol exposure induces reactive oxygen species, DNA damage, and cell death in vascular endothelial cells. Toxicol Sci 2016; 154: 332-340.

12. Rooban T, Mishra G, Elizabeth J, Ranganathan K, Saraswathi T. Effect of habitual arecanut chewing on resting whole mouth salivary flow rate and $\mathrm{pH}$. Indian J Med Sci 2006; 60: 95-105.

13. Zappacosta B, Persichilli S, De Sole P, Mordente A, Giardina B. Effect of smoking one cigarette on antioxidant metabolites in the saliva of healthy smokers. Arch Oral Biol 1999; 44: 485-488.

14. Mandel ID. The diagnostic uses of saliva. J Oral Pathol Med 1990; 19: 119-125.

15. Tanasiewicz M, Hildebrandt T, Obersztyn I. Xerostomia of various etiologies: a review of the literature. Adv Clin Exp Med 2016; 25: 199-206.

16. Mirzaii-Dizgah I, Agha-Hosseini F. Unstimulated whole saliva parathyroid hormone in postmenopausal women with xerostomia. J Contemp Dental Pract 2011; 12: 196-199.

17. Busato IM, Ignácio SA, Brancher JA, Moysés ST, AzevedoAlanis LR. Impact of clinical status and salivary conditions on xerostomia and oral health-related quality of life of adolescents with type 1 diabetes mellitus. Commun Dentistry Oral Epidemiol 2012 40: 62-69.

18. Mortazavi H, Baharvand M, Movahhedian A, Mohammadi M, Khodadoustan A. Xerostomia due to systemic disease: a review of 20 conditions and mechanisms. Ann Med Health Sci Res 2014; 4: 503-510.

19. Rad M, Kakoie S, Niliye Brojeni F, Pourdamghan N. Effect of longterm smoking on whole-mouth salivary flow rate and oral health J Dent Res Dent Clin Dent Prospects 2010; 4: 110-114.

20. Alterovitz SS, Mendelsohn GA. Relationship goals of middle-aged, young-old, and old-old Internet daters: an analysis of online personal ads. J Aging Studies 2013; 27: 159-165.

21. Pokhrel P, Herzog TA. Reasons for quitting cigarette smoking and electronic cigarette use for cessation help. Psychol Addict Behav 2015; 29: 114.

22. Zhu SH, Zhuang YL, Wong S, Cummins SE, Tedeschi GJ. E-cigarette use and associated changes in population smoking cessation: evidence from US current population surveys. BMJ 2017; 358: j3262.

23. Rigotti NA. Balancing the benefits and harms of e-cigarettes: a National Academies of Science, Engineering, and Medicine report. Ann Intern Med 2018; 168: 666-667.

24. Abrams DB, Glasser AM, Pearson JL, Villanti AC, Collins LK, Niaura RS. Harm minimization and tobacco control: reframing societal views of nicotine use to rapidly save lives. Annu Rev Public Health 2018; 39: 193-213.

25. Hajek P, Etter JF, Benowitz N, Eissenberg T, McRobbie H. Electronic cigarettes: review of use, content, safety, effects on smokers and potential for harm and benefit. Addiction 2014; 109: 1801-1810.

26. Shahab L, Goniewicz ML, Blount BC, et al. Nicotine, carcinogen, and toxin exposure in long-term e-cigarette and nicotine replacement therapy users: a cross-sectional study. Ann Intern Med 2017; 166: $390-400$
27. Goniewicz ML, Knysak J, Gawron M, et al. Levels of selected carcinogens and toxicants in vapour from electronic cigarettes. Tob Control 2014; 23: 133-139.

28. Williams M, Villarreal A, Bozhilov K, Lin S, Talbot P. Metal and silicate particles including nanoparticles are present in electronic cigarette cartomizer fluid and aerosol. PLoS One 2013; 8: e57987.

29. Farsalinos KE, Romagna G, Tsiapras D, Kyrzopoulos S, Voudris V. Characteristics, perceived side effects and benefits of electronic cigarette use: a worldwide survey of more than 19,000 consumers. Int J Environ Res Public Health 2014; 11: 4356-4373.

30. Eissenberg T, Bhatnagar A, Chapman S, Jordt SE, Shihadeh A, Soule EK. Invalidity of an oft-cited estimate of the relative harms of electronic cigarettes. Am J Public Health 2020; 110: 161-162.

31. Hilton S, Weishaar H, Sweeting H, Trevisan F, Katikireddi SV. E-cigarettes, a safer alternative for teenagers? A UK focus group study of teenagers' views. BMJ Open 2016; 6: e013271.

32. Brose LS, Bowen J, McNeill A, Partos TR. Associations between vaping and relapse to smoking: preliminary findings from a longitudinal survey in the UK. Harm Reduct J 2019; 16: 76.

33. Weinstein R, Francetti L, Maggiore E, Marchesi G. Alcohol and smoking. The risk factors for the oral cavity. Minerva Stomatol 1996; 45: 405-413.

34. Sham A, Cheung L, Jin L, Corbet E. The effects of tobacco use on oral health. Hong Kong Med J 2003; 9: 271-277.

35. Khan GJ, Mehmood R, ud-Din S, ul-Haq I. Effects of long-term use of tobacco on taste receptors and salivary secretion. J Ayub Med Coll Abbottabad 2003; 15: 37-39.

36. Fox PC, Busch KA, Baum BJ. Subjective reports of xerostomia and objective measures of salivary gland performance. J Am Dent Assoc 1987; 115: 581-584.

37. Gholami N, Hosseini Sabzvari B, Razzaghi A, Salah S. Effect of stress, anxiety and depression on unstimulated salivary flow rate and xerostomia. J Dent Res Dent Clin Dent Prospects 2017; 11: 247-252.

38. Cyrino RM, Miranda Cota LO, Pereira Lages EJ, Bastos Lages EM, Costa FO. Evaluation of self-reported measures for prediction of periodontitis in a sample of Brazilians. J Periodontol 2011; 82: 1693-1704.

39. Piuvezam G, de Lima KC. Self-perceived oral health status in institutionalized elderly in Brazil. Arch Gerontol Geriatr 2012; 55 : 5-11. 